Produto \& Produção, vol. 11, n. 2, p. 01 - 25, jun. 2010

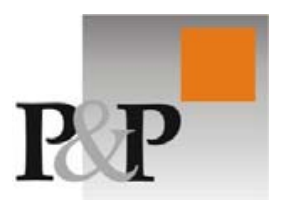

\title{
Desenvolvimento e Aplicação de uma Ferramenta Informatizada para Medição de Desempenho e Melhoria Contínua
}

\author{
Rafael Henrique Palma Lima \\ (EESC/USP) \\ Luiz Cesar Ribeiro Carpinetti
}

(EESC/USP)

\begin{abstract}
RESUMO
Se realizada de forma apropriada, a gestão de desempenho pode ser um diferencial para as empresas, fazendo com que elas obtenham resultados semelhantes ou até melhores que seus concorrentes e consigam sobreviver no mercado cada vez mais competitivo. Com o intuito de contribuir com esta área de pesquisa, novas ferramentas e métodos para a medição de desempenho devem ser propostos e a eficiência de cada um deve ser verificada através de aplicações práticas. Com base neste raciocínio, neste artigo é primeiramente proposto um método para construção de sistemas de medição de desempenho (SMD). Em seguida, é apresentado um software desenvolvido para acompanhar os indicadores de desempenho obtidos por meio deste método e para favorecer a execução de ações de melhoria que visam aprimorar os resultados de tais indicadores. Uma aplicação piloto do método e do software foi feita para testar seu funcionamento na prática. Com base nesta aplicação, pôde-se concluir que o método é eficiente na seleção de indicadores de desempenho. Já o software pode ser visto como uma boa maneira para comunicar os resultados do desempenho e favorecer a melhoria contínua.
\end{abstract}

Palavras-chave: Gestão de desempenho, balanced scorecard, sistemas de apoio à decisão.

\section{INTRODUÇÃO}

Diversos autores, tais como Kaplan e Norton (1997), Neely, Gregory e Platts (1995) e Bourne, Kennerley e Franco-Santos (2005) discutem a importância da gestão do desempenho para as empresas que desejam atingir seus objetivos estratégicos. De forma geral, estes autores argumentam que deve haver uma coerência entre a estratégia e as ações realizadas pela empresa. Por isso, a gestão 
de desempenho deve ser feita com base em indicadores que estejam de acordo com os objetivos estratégicos da organização.

Este alinhamento com a estratégia tem relação com as ações que as empresas devem tomar para atingir seus objetivos. Isto está de acordo com a filosofia de autores como Campos (1996) e Collins e Huge (1993), que argumentam que as organizações devem estabelecer planos estratégicos de curto, médio e longo prazo. Nesses planos, metas vitais devem ser definidas e todas as ações realizadas devem sustentar e contribuir para o atingimento das metas. Num ambiente como esse, os indicadores de desempenho têm como papel mensurar o posicionamento da empresa em relação às metas estabelecidas em todos os níveis organizacionais.

Um dos problemas enfrentados pelas empresas que fazem uso de indicadores de desempenho é a quantidade elevada de dados que devem ser processados e analisados. Segundo autores como Hikage, Spinola e Laurindo (2006) e Olve, Roy e Wetter (2001), a construção de sistemas de informação específicos para a gestão de desempenho pode facilitar o processo de coleta, organização e análise de dados. No entanto, para receber esse tipo de software, não basta que a empresa possua toda a estrutura física e computacional necessária. É preciso que haja um grande comprometimento de todas as áreas da empresa em relação ao uso correto do sistema de gestão de desempenho. Isso requer, além do treinamento dos funcionários envolvidos com a coleta e análise de dados, uma mudança cultural e comportamental das pessoas.

Assim, pode-se perceber que se uma empresa deseja iniciar a gestão de desempenho de forma apropriada, dois itens essenciais devem ser desenvolvidos:

- Um método para obter objetivos estratégicos, metas e indicadores de desempenho que estejam alinhados com os objetivos existentes nos planejamentos de curto, médio e longo prazo da empresa;

- Um sistema informatizado para armazenar os dados de desempenho e das ações realizadas ao longo de toda a organização;

Com base nesta constatação, o objetivo deste artigo é propor um método para a construção de sistemas de medição de desempenho composto por indicadores relacionados com a estratégia organizacional e apresentar um software desenvolvido para o acompanhamento de tais indicadores e das ações de melhoria que podem vir a ser executadas pela empresa como forma de aprimorar seu desempenho. Para demonstrar a eficiência do método e do software, este trabalho apresenta o relato de uma aplicação prática, do qual diversas conclusões e reflexões puderam ser tiradas.

Para atingir este objetivo, primeiramente é realizado um levantamento bibliográfico sobre medição de desempenho, dando ênfase ao Balanced Scorecard, que foi o framework escolhido para estruturar o software de gestão de desempenho. Como o software pode ser visto como uma fonte de dados para a tomada de decisão, os Sistemas de Apoio à Decião (SADs) também são abordados na revisão bibliográfica. Um estudo de caso em uma empresa de grande porte que possui um sistema formalizado de medição de desempenho foi feito para inspirar os requisitos e funcionalidades para o software proposto neste artigo. Os conhecimentos obtidos com a revisão bibliográfica e o estudo de caso foram reunidos para se refinar os requisitos do software e os passos do método para construção do SMD. Por fim, o método e o software foram aplicados em uma empresa fabricante de caldeiras. As seções a seguir descrevem todos esses passos. Ao final do artigo são discutidos os resultados da aplicação piloto. 


\section{REFERENCIAL TEÓRICO}

Esta seção faz uma revisão bibliográfica sobre Sistemas de Medição de Desempenho, Balanced Scorecard (BSC) e Sistemas de Apoio à Decisão (SAD), que são os temas que fundamentam tanto o método quanto o software propostos neste artigo.

\subsection{Sistemas de medição de desempenho}

A medição de desempenho é um processo crítico para o sucesso das empresas e o interesse pelo assunto vem crescendo continuamente desde a década de 1970. Bourne et al. (2000) destacam que desde a década de 1970, os autores vinham ressaltando as deficiências dos SMDs da época, pois estes se baseavam demasiadamente em medidas financeiras. Isso fez com que, nas décadas de 1980 e 1990, houvesse um grande interesse em propor novas formas para a medição de desempenho que balanceassem indicadores financeiros e não-financeiros.

Neely (1999) afirma que a medição de desempenho está presente nas empresas desde o início do século 20. No entanto, o assunto passou a entrar na agenda dos pesquisadores apenas a partir da década de 80. Segundo esse autor, vários motivos levaram a este repentino aumento do interesse pelo assunto, sendo eles o aumento da competição, as iniciativas pela melhoria da qualidade, as mudanças na natureza do trabalho e o poder da tecnologia da informação.

As décadas de 1980 e 1990 foram caracterizadas pela criação de novos frameworks para a medição de desempenho que tentavam se afastar das medidas financeiras e alinhar o SMD à estratégia organizacional (NEELY et al. 2000; NEELY, 2005). Dentre os modelos criados nesta época, podem ser mencionados o Performance Pyramid (LYNCH; CROSS, 1991), o Performance Measurement Matrix (KEEGAN et al. 1989), o Balanced Scorecard (KAPLAN; NORTON, 1992) e o Performance Prism (NEELY et al. 2001; ADAMS; NEELY, 2000).

No que se refere à definição dos SMDs, Neely, Gregory e Platts (1995) colocam que este é um tema amplamente estudado, mas que raramente é definido. Para facilitar o entendimento desse assunto, os autores dão definições para três termos:

- Medição de desempenho: processo para a quantificação da eficiência e eficácia das ações;

- $\quad$ Medida de desempenho: métrica usada para quantificar a eficiência e a eficácia de uma ação;

- $\quad$ Sistema de medição de desempenho: conjunto das métricas usadas para quantificar tanto a eficiência quanto a eficácia das ações.

Olsen et al. (2007) apresentam um método para analisar a efetividade de um SMD baseado em três critérios que eles consideram vitais. Tais critérios são:

- Causalidade: as relações de causa-e-efeito entre os indicadores de desempenho têm como objetivo integrar as métricas, alinhando-as à estratégia organizacional;

Melhoria contínua: o objetivo do SMD em uma empresa é melhorar seu desempenho. Portanto, um bom SMD deve ser capaz de identificar tendências no 
desempenho, ajudando na definição de metas e, consequentemente, facilitando a melhoria contínua;

- $\quad$ Controle de processos: o controle de processos na manufatura tem um papel-chave na diminuição de estoques e variabilidade, que por sua vez tem um grande impacto no desempenho organizacional.

Em resumo, os SMDs podem ser vistos como um conjunto de métricas alinhadas aos objetivos estratégicos da empresa por meio de relações de causa-eefeito. No entanto, a mera existência desses dados não é suficiente para melhorar o desempenho organizacional. Tais dados devem ser processados e analisados para gerar informações que guiem a empresa na elaboração de ações que promovam a melhoria contínua. Caso contrário, todo o investimento feito em medição poderá não trazer o retorno financeiro esperado.

\subsection{Balanced scorecard}

O Balanced Scorecard (BSC) é um dos mais difundidos frameworks para construção de SMDs (NEELY, 2005; ATKINSON, 2006; VOELPEL et al., 2006). Muitos pesquisadores se dedicam a estudar sua aplicação e seus impactos nas empresas (NEELY, 2005). Sua principal característica é a organização dos indicadores de desempenho em quatro perspectivas: financeira, clientes, processos internos e aprendizado e crescimento. O objetivo do BSC é alinhar os indicadores de desempenho aos objetivos estratégicos da empresa por meio dessas perspectivas, que podem ser vistas na Figura 1. A pedra fundamental do BSC é a estratégia organizacional, que deve ser usada como base para a definição de todos os objetivos, indicadores, metas, etc.

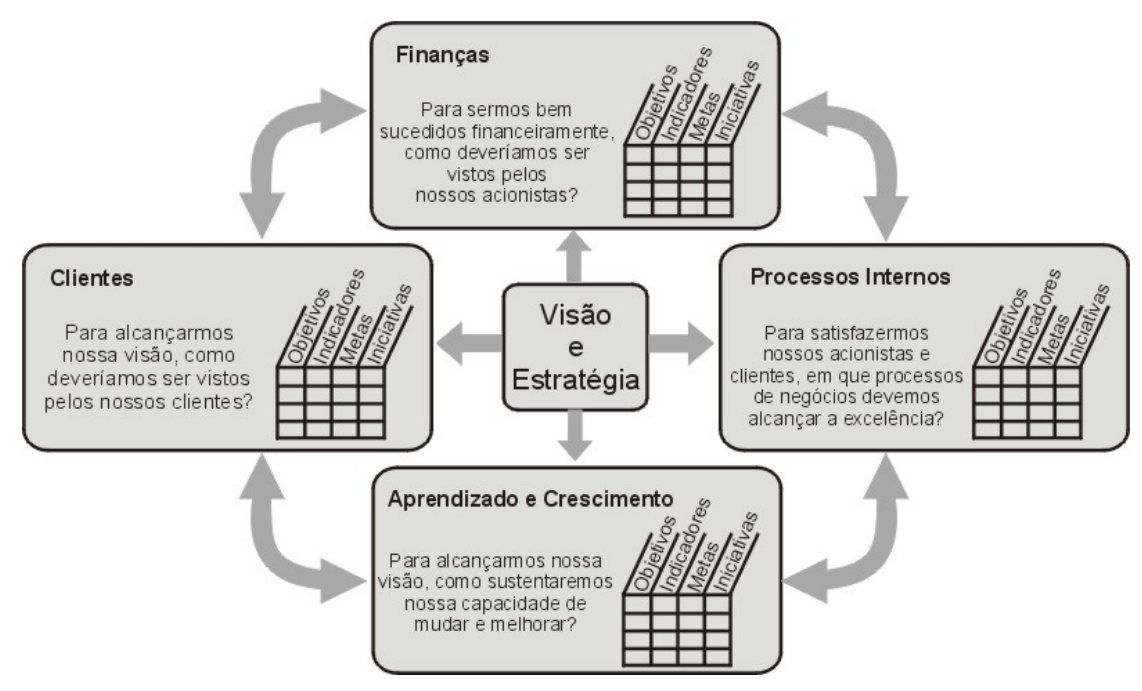

Figura 1: Perspectivas do Balanced Scorecard Fonte: Kaplan e Norton (1997)

Kaplan e Norton (1992) definem o BSC como um conjunto de medidas que dão aos gestores uma visão ampla e rápida do negócio. Segundo eles, isso é feito pela combinação de medidas financeiras, que contam os resultados das ações já 
tomadas, com medidas complementares, como resultados operacionais, satisfação do cliente, processos internos e as atividades de melhoria e inovação.

Outra característica importante do BSC, segundo Kaplan e Norton (1997), são as relações de causalidade existentes entre os indicadores de desempenho. Segundo esses autores, todos os indicadores de desempenho devem fazer parte de uma cadeia de relações de causa-e-efeito que culmine na melhora dos resultados financeiros da empresa. As relações de causalidade foram posteriormente aprimoradas com a criação dos mapas estratégicos (KAPLAN; NORTON, 2004). O foco dos mapas estratégicos está na forma em que ativos intangíveis como conhecimento, força de trabalho e sistemas de informação são transformados em ativos tangíveis (KAPLAN; NORTON, 2001).

As dimensões do BSC são de fácil compreensão. Contudo, Folan e Browne (2005) argumentam que o BSC é um framework estrutural para medição de desempenho. Ou seja, ao mesmo tempo em que ele facilita a estruturação dos indicadores em dimensões, não há um procedimento preciso para sua implantação. Neely et al. (2000) destaca ainda que não há para o BSC, um procedimento para a escolha de quais indicadores devem fazer parte do sistema de medição de desempenho. Chavan (2009) sintetiza o processo de construção de um BSC em quatro passos:

Clarear e traduzir a visão em estratégia;

Comunicar e ligar objetivos estratégicos e medidas;

Planejar, definir metas e alinhas iniciativas estratégicas;

Aprimorar o aprendizado e o feedback estratégico.

Apesar de seu sucesso comercial, o BSC é criticado por diversos autores. Norreklit (2000) critica a forma simplista em que alguns dos conceitos fundamentais do BSC são apresentados. Essa autora também questiona a maneira em que as ações de causalidade são apresentadas por Kaplan e Norton (1997). Para ela, essas relações formam apenas uma cadeia lógica de eventos, e não uma cadeia de relações de causa-e-efeito que possa ser testada empiricamente. Outros autores, como Neely, Adams e Crowe (2001) e Brignall (2002) criticam a ausência de importantes stakeholders na construção do scorecard. Para esses autores, o BSC foca apenas os clientes, acionistas e funcionários, deixando de lado o meioambiente, questões sociais, legislação e regulamentos.

\subsection{Sistemas de apoio à decisão}

Os sistemas de apoio à decisão são fortemente ligados à medição de desempenho, uma vez que, para tomarem decisões, os executivos necessitam de informações operacionais que, em muitas vezes, são oriundas de indicadores de desempenho. Dessa forma, os SMDs se tornam uma das principais fontes de dados para a tomada de decisões (NUDURUPATI; BITITCI, 2005).

Os indicadores de desempenho, por si só, não são capazes de fazer muito pela organização. No entanto, o uso destas informações para a tomada de decisões e criação de iniciativas de melhoria pode elevar o desempenho da empresa. Essa afirmação está de acordo com a definição de gestão de desempenho feita por Amaratunga e Baldry (2002). Segundo esses autores, a gestão de desempenho consiste no uso das informações da medição de desempenho para causar mudanças positivas na cultura organizacional, sistemas e processos. Tais 
informações podem ser usadas para redefinir metas e objetivos e devem ser compartilhadas entre as pessoas que buscam seu atingimento.

Gomes, Yasin e Lisboa (2004) mostraram que as empresas vêm crescentemente usando indicadores de desempenho não-financeiros em seu processo diário de tomada de decisão, apesar de que ainda há pouca evidência quanto à ligação destes indicadores à estratégia organizacional.

Para Poe, Klauer e Brobst (1997), um sistema de apoio à decisão é um sistema que fornece informações aos usuários para que eles possam analisar uma situação e tomar decisões. Para eles, estes sistemas podem ser usados por funcionários de todos os níveis, tornando seus trabalhos mais efetivos. As decisões podem ser estratégicas, por meio de análises a longo-prazo, ou táticas, em que são incluídos problemas de curto-prazo.

Turban e Ronson (2001) definem os SADs como uma metodologia ou abordagem para apoiar a tomada de decisões. Tal metodologia faz uso dos sistemas de informação especialmente desenvolvidos para o tratamento de problemas gerenciais não estruturados. Seu objetivo é possibilidar ao gerente a reflexão sobre problemas com base em dados e modelos interativos.

Segundo O'Brien (2004), os SADs são uma categoria dos Sistemas de Apoio Gerencial (SAGs), que têm como função fornecer informações e apoio aos gerentes em sua tomada de decisão. O autor define três tipos de sistemas derivados dos SAGs:

Sistemas de Informação Gerencial (SIG): Fornecem informações sob a forma de relatórios e demonstrativos para os gerentes;

Sistemas de apoio à decisão (SAD): Fornecem apoio interativo ad hoc para a tomada de decisões. São usados para análise de cenários, elaboração de previsões, análise de riscos;

Sistemas de informação executiva (SIE): Reúnem informações críticas elaboradas especificamente para os executivos. Tais sistemas provêem acesso rápido ao desempenho empresarial, ações dos concorrentes e desenvolvimento econômico.

Os SIEs têm foco nos executivos de alto nível da organização. Seu objetivo é abstrair a grande quantidade de dados armazenados nas diversas bases de dados da empresa de forma a torná-los compreensíveis aos usuários finais. Neste sentido, Basu et al. (2000) definem um SIE como sendo um sistema de informação integrado que:

- $\quad$ Extrai, filtra e rastreia dados;

- $\quad$ Provê funcionalidades do tipo drill-down para detalhamento de informações em níveis inferiores; fora da organização;

Acessa uma grande diversidade de fontes de dados, tanto dentro como

Possui uma interface de usuário bastante amigável que apresenta informações em forma de tabelas, gráficos ou texto;

- $\quad$ Geralmente é desenvolvido para seguir o estilo de tomada de decisões específico dos executivos. 


\subsection{Abordagem conjunta para a gestão de desempenho}

Os temas apresentados na revisão teórica são complementares entre si e devem ser aplicados conjuntamente para que a gestão de desempenho seja eficaz dentro das empresas. De fato, toda empresa em algum momento implementa indicadores de desempenho dentro de seu processo gerencial. Contudo, no caso de empresas pequenas e sem um sistema de gestão propriamente dito, o que se observa é que muitos desses indicadores são criados de forma a resolver problemas pontuais e não são incorporados ao processo gerencial da organização. Outras empresas até possuem um conjunto de indicadores que são frequentemente avaliados, mas eles muitas vezes têm um foco demasiadamente financeiro ou não estão ligados aos objetivos estratégicos (SOUZA et al. 2006; HUDSON et al. 2001).

A Figura 2 mostra a relação entre os elementos que formam a gestão do desempenho, com foco na tecnologia de informação e tomada de decisão. Frameworks como o BSC servem para auxiliar a empresa na construção de um SMD que a ajude a cumprir sua estratégia. Nesse estágio, o SMD deixa ser apenas um conjunto de indicadores de desempenho informalmente estruturado para ser um sistema composto por indicadores interligados por relações de causalidade e classificados de acordo com as perspectivas de desempenho do BSC.

Após a construção do SMD, os indicadores passam a ser usados no dia a dia da empresa. O cálculo de indicadores depende de dados que podem estar armazenados em fontes computadorizadas ou em registros manuais. O sistema de informação para comunicação e gestão de desempenho é desenvolvido segundo os requisitos do SMD e faz uso dos dados empregados no cálculo dos indicadores. Esse SI deve ser capaz de apresentar dados, gerar relatórios, comunicar resultados e possibilitar a navegação pelos indicadores. Quando o usuário tem acesso a esse tipo de informação, ele se torna capaz de tomar decisões mais precisas e elaborar ações de melhoria que atinjam os problemas de maior prioridade na organização. As decisões tomadas podem ter como objetivo tanto a melhoria dos indicadores atualmente existentes no SMD como a atualização do sistema de indicadores em uso. Tal atualização pode se tornar necessária quando o usuário perceber que o conjunto de indicadores existente não atende mais a demanda de informação requerida para fundamentar a tomada de decisão. Assim, novos indicadores podem ser incluídos no SMD e outros excluídos. 


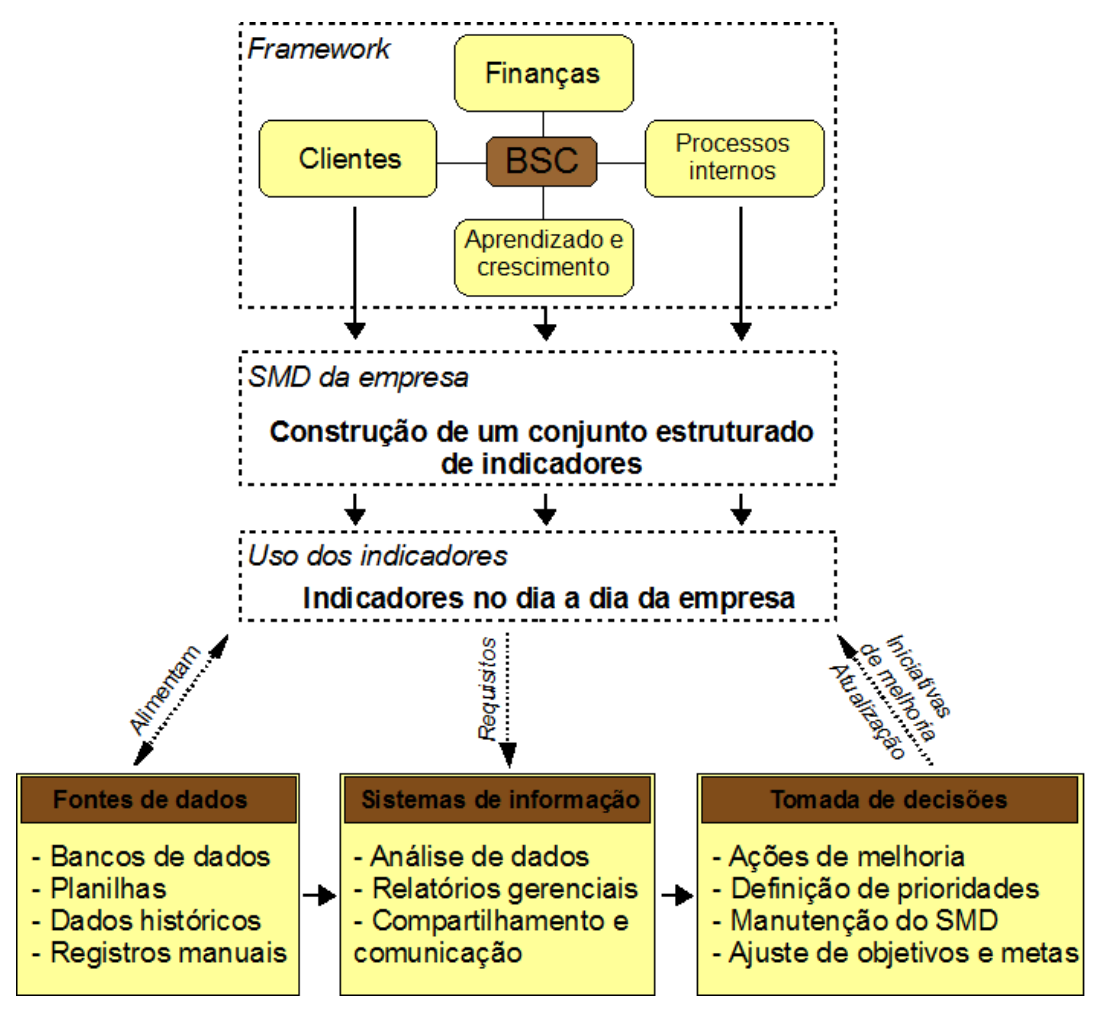

Figura 2: Relacionamento entre os elementos da gestão de desempenho

\section{ESTUDO DE CASO}

Para alcançar os objetivos deste trabalho, tornou-se necessário conhecer um caso real de uso de SMD. Com o intuito de identificar características a serem incorporadas no software e no método aqui propostos, um estudo de caso foi realizado em uma empresa de grande porte que produz bens de capital seriados, sendo eles máquinas-ferramenta, tornos $\mathrm{CNC}$, máquinas injetoras de plástico e centros de usinagem. Durante a elaboração deste estudo, deu-se ênfase ao método usado pela empresa para desenvolver seu SMD, à estruturação dos indicadores e ações de melhoria e aos meios de análise e comunicação dos resultados.

À época da realização deste estudo, a empresa já possuía um SMD em funcionamento há cerca de dois anos. Como ela possui a certificação ISO 9001, foi necessário incorporar o SMD às suas normas de procedimento. Isso fez com que a empresa precisasse formalizar o SMD, tanto no que se refere a documentos quanto ao comprometimento dos funcionários com o sistema. Segundo os funcionários responsáveis pelo sistema, esse foi um fator que favoreceu o sucesso da medição de desempenho.

A construção do SMD se deu a partir do desdobramento da visão, valores e políticas da empresa, seguindo o método proposto por Campos (1996). Com isso, foram definidos quatro fatores-chave de desempenho, dos quais foram derivadas as diretrizes e os indicadores de desempenho. São eles:

Qualidade: este fator-chave engloba as diretrizes e os indicadores relacionados à satisfação dos clientes internos e externos. O conceito de qualidade envolve a ausência de defeitos e as características que irão satisfazer os clientes. 
Aqui também é levada em conta a qualidade das informações, dos treinamentos e a confiabilidade das operações;

Custo: engloba diretrizes e indicadores ligados ao custo final e intermediário dos produtos, tais como custo médio de compras e custo de recrutamento e seleção. Outros indicadores financeiros também se encontram nesta categoria, tais como o faturamento e o lucro líquido;

Entrega: o processo de entrega é um fator-chave considerado à parte pela empresa. Aqui estão as diretrizes e indicadores para a entrega de produtos e serviços finais e intermediários. Exemplos de indicadores são: pontualidade na entrega; entregas em locais errados; entregas em quantidades corretas;

Pessoas: leva em conta o nível de satisfação dos colaboradores, tanto ao nível departamental como ao nível global da empresa. Indicadores para este fator estão relacionados com a rotatividade de pessoal, absenteísmo e índice de treinamento e capacitação.

A cada um desses indicadores são associadas metas de desempenho criadas pelos diretores da empresa. Além disso, pode-se associar ações de melhoria aos indicadores de desempenho, o que objetiva a melhoria dos resultados de tais indicadores e caracteriza a melhoria contínua do desempenho. Com base nestes elementos, a Figura 3 sintetiza a estrutura do SMD da empresa pesquisada.

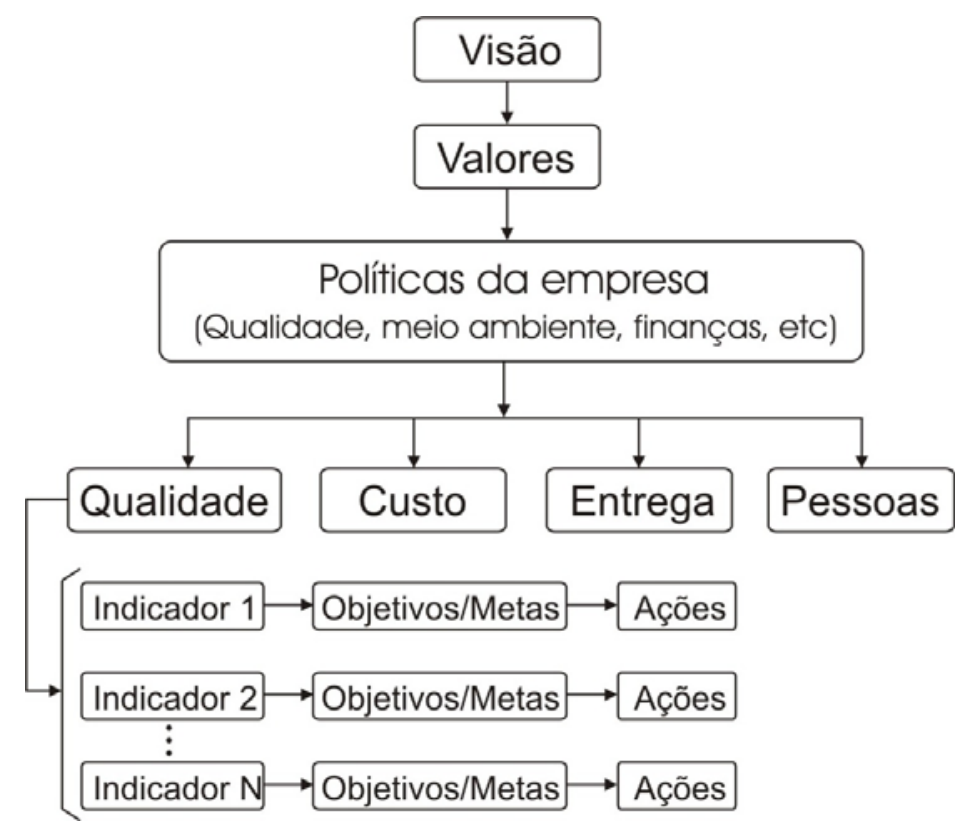

Figura 3: Processo de desdobramento dos indicadores de desempenho

A comunicação do desempenho dentro da empresa é feita por meio de planilhas eletrônicas, nas quais as metas e o desempenho corrente são apresentados em gráficos de controle e de tendência. A empresa não possui um sistema informatizado específico para a medição de desempenho. No entanto, há um software de apoio à decisão que analisa os dados armazenados no sistema de informação corporativo (ERP) e constrói relatórios com informações que não podem ser encontradas apenas pelo uso dos indicadores de desempenho. Tais análises são feitas para auxiliar em decisões pontuais. Assim, os indicadores que fazem parte do SMD formal podem ser combinados com os relatórios provenientes desse SAD de forma a fornecer mais fatos para a tomada de decisão. 
Com relação à avaliação do desempenho, a empresa definiu que todo mês os resultados apurados dos indicadores devem passar por uma análise crítica feita através de uma reunião na qual participam os responsáveis de todas as áreas da empresa. Nessa reunião são definidas as ações para melhorar o desempenho. Além disso, metas podem ser ajustadas para adaptar o SMD a eventuais mudanças internas ou externas. Ao final do ano, os diretores, funcionários ligados ao SMD e os gerentes das principais áreas da empresa se reúnem novamente para discutir tanto os resultados do ano quanto as novas metas e ações para o ano seguinte.

\section{PROPOSTA DO SOFTWARE E DO MÉTODO DE CONSTRUÇÃO DO SMD}

Um método baseado no BSC para a definição de indicadores de desempenho e objetivos estratégicos é apresentado nesta seção. Em seguida, um software para o acompanhamento e comunicação do desempenho dentro da organização é apresentado, incluindo seus requisitos, organização e funcionalidades. Tanto o método quanto o software foram elaborados com base nos conhecimentos obtidos com o levantamento bibliográfico e com o estudo de caso.

\subsection{Método para desenvolvimento do SMD}

Para que seja possível construir um SMD dentro de uma empresa é necessário um método que guie tal desenvolvimento com base em um conjunto de etapas e conceitos. O método deve ser elaborado de forma a garantir que sua aplicação atingirá as expectativas das empresas e será efetivo e eficaz no cumprimento de seu papel. Para isso, é necessário baseá-lo em conceitos já testados na prática por pesquisadores e empresas para aumentar suas chances de sucesso.

O Balanced Scorecard foi selecionado para formar a base do método aqui proposto. Apesar de ser criticado por alguns autores, o BSC é certamente o framework mais usado e aceito comercialmente (NEELY, 2005). Diversos softwares comerciais atualmente implementam o BSC para controle de objetivos estratégicos e indicadores de desempenho. Para Kaplan e Norton (1997), o uso de perspectivas e relações de causa-e-efeito entre os objetivos estratégicos facilita a visualização da estratégia organizacional, o que pode ser um fator determinante para o sucesso deste framework.

O método apresentado por Kaplan e Norton (1997) para a construção de um BSC pode ser resumido em quatro passos:

- $\quad$ Passo 1: Seleção de uma unidade de negócios da corporação e compreensão de seu papel e relações com outras unidades de negócios;

- $\quad$ Passo 2: Definição preliminar dos objetivos e indicadores para cada perspectiva;

- $\quad$ Passo 3: Refinamento e elaboração dos indicadores;

- $\quad$ Passo 4: Elaboração do plano de implementação. 
Todas as etapas anteriormente listadas devem ser conduzidas com base em entrevistas com os principais executivos da unidade de negócios. Pode-se perceber que a lógica da construção de um BSC parte da percepção que os executivos têm sobre os objetivos estratégicos. Portanto, as entrevistas devem ser capazes de levantar dados suficientes para que haja um consenso entre todos os executivos quanto aos objetivos definidos. Após isso, os objetivos e indicadores de desempenho são refinados através de workshops até que eles se tornem consistentes. Por fim, um plano de implementação é elaborado para indicar as fontes de dados para cada indicador e os meios para sua comunicação dentro da empresa.

Outro método de desenvolvimento de SMDs adotado neste trabalho é o desenvolvido por Rentes, Carpinetti e Aken (2002). Tal método consiste nos seguintes passos:

- $\quad$ Passo 1: Identificar objetivos estratégicos;

- $\quad$ Passo 2: Identificar áreas-chave de desempenho;

- $\quad$ Passo 3: Definir indicadores de alto nível relacionados às áreas-chave;

- $\quad$ Passo 4: Desdobrar indicadores (1 nível);

- $\quad$ Passo 5: Projetar sistema de visualização e comunicação de:

1. Indicadores;

2. Plano de ação;

- $\quad$ Passo 6: Planejamento da operacionalização do sistema.

Neste conjunto de passos, é possível encontrar características semelhantes ao BSC. Aqui, a construção do SMD também parte da identificação de objetivos estratégicos que são relacionados com as áreas-chave de desempenho. Após isso são definidos os indicadores relacionados diretamente com as áreas-chave. O que há de diferente neste método é o desdobramento dos indicadores em um nível, o que aumenta o detalhamento dos dados coletados em níveis inferiores na hierarquia. Outra diferença está na preocupação em como comunicar os resultados de indicadores e planos de ação para as pessoas que necessitam destas informações.

Rentes, Carpinetti e Aken (2002) recomendam que os indicadores sejam comunicados em quadros de visibilidade, onde as métricas podem ser visualizadas facilmente pelas pessoas interessadas. Elas devem ser apresentadas de forma que os funcionários possam compreender o desempenho geral organizacional. Também é importante atualizar esses quadros regularmente para refletir a realidade corrente da organização.

Os passos apresentados anteriormente em ambos os modelos foram refinados para sua aplicação específica neste trabalho. A maior parte das empresas brasileiras que poderiam fazer uso do método aqui proposto é bem menor que as usadas por Kaplan e Norton (1997) para mostrar o BSC em funcionamento. Por isso, este novo método deve ir ao encontro das características de organizações mais simples.

Em tais empresas, não existem muitos recursos financeiros e humanos disponíveis para a criação de uma equipe exclusiva para desenvolver o SMD. Por isso, a equipe de desenvolvimento deve ser multifuncional e esse trabalho deve tomar apenas uma pequena parte de seu tempo. Outra característica de tais empresas é a administração familiar, em que apenas um pequeno conjunto de sócios toma conta de todo o negócio. Dessa forma, não existem muitos executivos para as entrevistas, o que torna necessário o uso de outros funcionários para a coleta de dados sobre objetivos e indicadores. Considerando tais características, o 
método proposto para construção de SMD nesta pesquisa consiste nos seguintes passos:

- $\quad$ Passo 1: Compreensão do negócio da empresa através de entrevistas preliminares com os diretores. Nesta etapa também se deve verificar a opinião dos executivos quanto às perspectivas de desempenho, objetivos estratégicos e indicadores estratégicos;

- $\quad$ Passo 2: Entrevistas com os responsáveis pelas principais áreas para levantamento de indicadores de desempenho atualmente em uso. Também devem ser levantadas sugestões de novos indicadores que poderiam ser implementados nestes setores;

- $\quad$ Passo 3: Compilação das informações obtidas nas entrevistas para a formulação de uma primeira versão do SMD, composto pelas perspectivas, objetivos e indicadores. Nesta formulação, os indicadores já podem ser desdobrados em um nível, caso haja necessidade. Também deve ser planejado o meio de visualização e comunicação de indicadores. Esta versão deve ser apresentada para os entrevistados em um workshop para que sugestões de melhoria sejam dadas;

- $\quad$ Passo 4: Reformulação do SMD com as sugestões dadas no workshop e realização de uma nova reunião para aprovação do sistema proposto e elaboração de um plano de implementação.

Passo 5: Execução do plano de implementação e elaboração de diretrizes para a manutenção periódica do sistema.

Os passos aqui apresentados são uma adaptação dos dois métodos apresentados anteriormente às características das empresas que foram pesquisadas. Pode-se perceber que a base está no BSC, com a diferença que os responsáveis pelas áreas-chave também fazem parte das entrevistas. 0 desdobramento de indicadores é introduzido no passo 3, durante a compilação dos dados. A manutenção do sistema, conforme sugerem Wisner e Fawcett (1991) e Neely, Bourne e Kennerley (2000), deve ser feita periodicamente para que ele possa melhorar continuamente e se adaptar às mudanças no ambiente interno e externo.

\subsection{Requisitos do software}

O software desenvolvido tem como objetivo principal fornecer informações aos gerentes e executivos sobre o andamento dos indicadores de desempenho e ações de melhoria, que são organizados segundo as perspectivas do Balanced Scorecard. O software busca facilitar o acesso às informações e a rápida visualização da situação corrente da empresa através de gráficos, gauges e tabelas.

Com base na bibliografia pesquisada e nas experiências adquiridas com 0 estudo de caso, propõem-se os seguintes requisitos para o software:

1. Possuir uma interface gráfica simples e intuitiva, na qual através de poucos cliques o usuário possa encontrar a informação desejada;

2. Detalhamento de informações de indicadores de desempenho, quando necessário;

3. Estruturação de indicadores de acordo com as perspectivas de desempenho e objetivos estratégicos; 
4. Apoiar a aplicação de ações de melhoria e associá-las aos indicadores de desempenho;

5. Gerar relatórios sobre os dados dos indicadores de desempenho e sobre o desempenho organizacional como um todo;

6. Gerar relatórios relacionados às ações de melhoria;

7. Armazenamento dos dados em um banco de dados, aumentando a segurança e a agilidade na criação de relatórios;

8. Controle de usuários, limitando o acesso a funcionalidades e informações a usuários de áreas diferentes da empresa;

Devido a estas características, o software pode ser classificado como um Sistema de Informação Executiva (SIE). Segundo a definição apresentada por O'Brien (2004), os SIEs fornecem informações críticas da empresa, especialmente sobre os indicadores de desempenho, e são voltados às necessidades dos executivos. O software aqui apresentado também pode ser visto como um SAD, pois pode ser usado em níveis altos e intermediários de gerência como fonte de dados para a tomada de decisões. Contudo, o software se limita a fontes de dados internas, o que o torna um SAD limitado. As fontes de dados externas devem, portanto, ser tratadas manualmente pelos funcionários responsáveis pela captação destes dados.

\subsection{Organização do sistema}

Um sistema de medição de desempenho pode envolver funcionários de toda a empresa, sendo que cada um tem suas responsabilidades quanto ao fornecimento e análise de dados. No caso do software desenvolvido neste trabalho, podemos identificar dois tipos básicos de usuário:

- $\quad$ Usuário executivo: este tipo de usuário inclui os diretores e executivos que usam o sistema para consultas e análises rápidas sobre o desempenho da organização. Seu papel é apenas usar os dados do sistema para apoio à decisão, não cabendo a eles a inserção de dados;

- Usuário operacional: os usuários operacionais trabalham dentro das diversas áreas da organização e têm o papel de alimentar o sistema com os dados sobre os indicadores de desempenho. Cada indicador possui um usuário que é o responsável por seu cálculo e cadastramento no sistema. Eventualmente, os usuários operacionais podem fazer consultas e gerar relatórios referentes aos dados cuja responsabilidade é sua.

Um SMD informatizado pode ser acessado por uma grande quantidade de usuários. Por isso, é importante que ele esteja disponível para toda a empresa através da rede de computadores. Isto pode ser feito através de um servidor central que armazena tanto o banco de dados como a aplicação em si. Dessa forma, todos os computadores que estiverem na mesma rede do servidor terão acesso aos dados e ao software. Concorrentemente ao software de medição de desempenho, as empresas podem ter a sua disposição um sistema ERP para o gerenciamento de suas transações. Os dados transacionais configuram uma das fontes de dados para o cálculo de indicadores. O uso do ERP é feito basicamente pelos usuários operacionais, que alimentam o sistema com dados e fazem consultas de relatórios 
operacionais. Esses usuários também podem usar o software SMD para consultar indicadores de desempenho que já sintetizem as informações transacionais e gerenciar ações de melhoria. Os usuários executivos, por sua vez, usam o software SMD para acompanhar indicadores, metas, gerir ações de melhoria e tomar decisões. É importante ressaltar que no nível dos usuários executivos, os dados de diversas fontes já estão compilados e organizados de forma a proporcionar um melhor contexto para tomada de decisões. A Figura sintetiza a relação do software proposto com os demais elementos da organização.

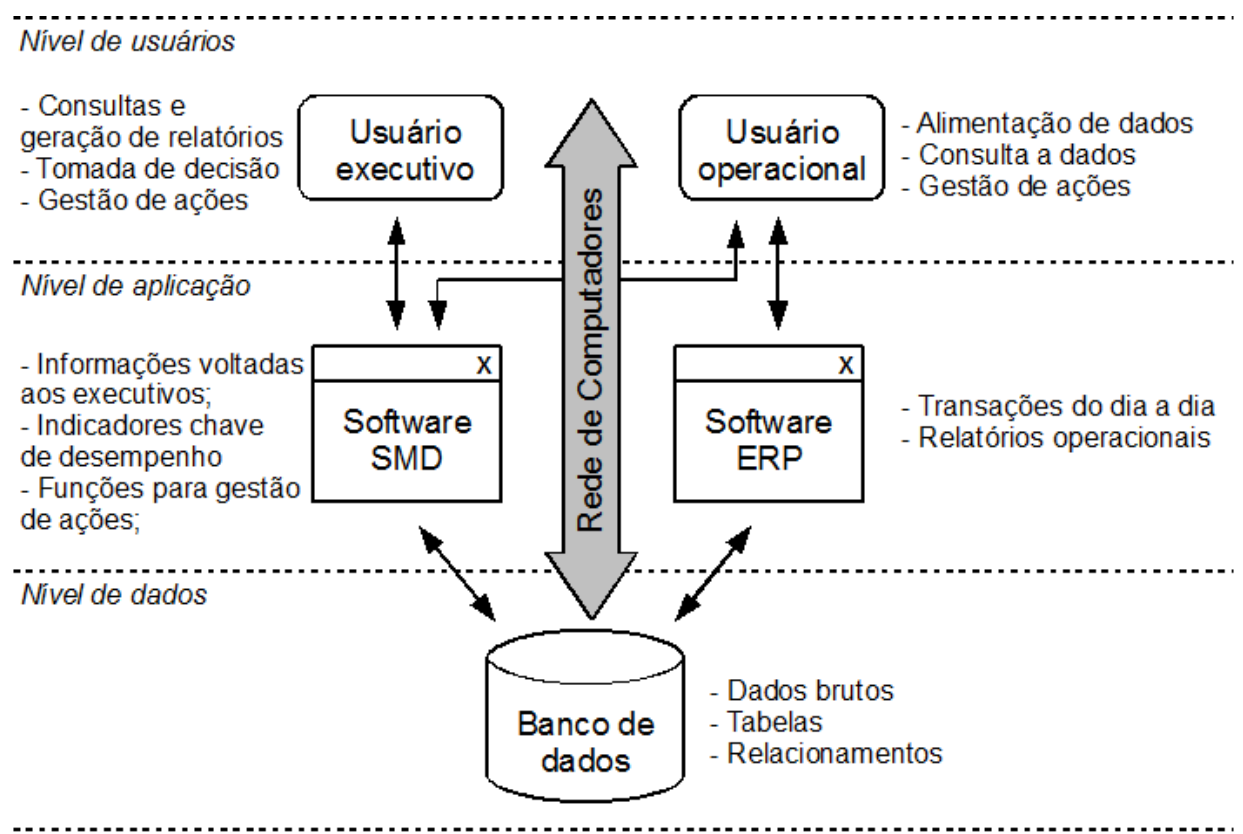

Figura 4: Organização do software para medição de desempenho

Quanto à organização dos dados, o sistema deve organizar os indicadores de desempenho seguindo a hierarquia da Figura 5 . Com isso, o software permite a criação de perspectivas de desempenho que atendam as necessidades do usuário. Cada objetivo de desempenho está relacionado a exatamente uma perspectiva por meio de uma ligação do tipo 1 para n. Por isso, cada perspectiva pode possuir diversos objetivos, mas um objetivo pertence a apenas uma perspectiva.

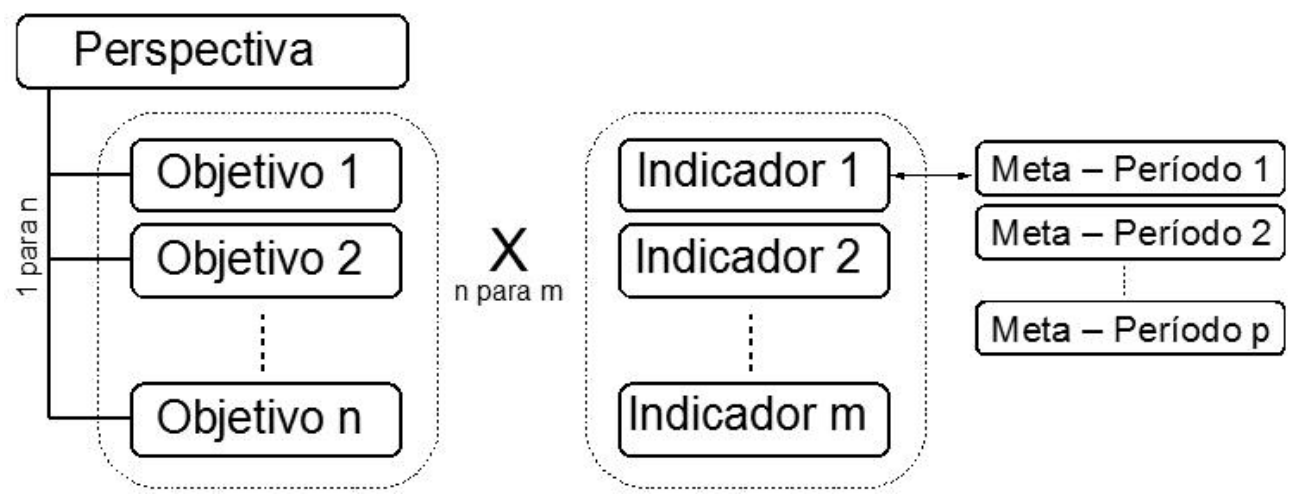

Figura 5: Relação entre os elementos do SMD 
Os indicadores de desempenho podem estar relacionados a vários objetivos estratégicos que, por sua vez, podem usar vários indicadores simultaneamente para sua avaliação. O objetivo de se associar indicadores a objetivos estratégicos é permitir que os usuários possam acompanhar se a empresa está conseguindo ou não cumprir seus objetivos por meio de dados numéricos. Por isso, a relação entre objetivos e indicadores deve ser do tipo $\mathrm{n}$ para $\mathrm{m}$, já que um indicador pode ser útil para vários objetivos e um objetivo único pode necessitar mais de um indicador para sua mensuração. Por fim, a cada indicador há diversas metas associadas. Cada uma delas se refere a um período diferente e um determinado indicador não pode ter metas cujos períodos se sobreponham.

Outro elemento importante da organização do sistema é a gestão das ações de melhoria. Tais ações podem ser criadas pelos usuários como projetos que visam obter pequenas melhorias para alguns indicadores de desempenho. No sistema proposto, cada uma destas ações está ligada a um objetivo estratégico e pode ter efeito sobre um número indefinido de indicadores de desempenho. A Figura 6 mostra tal relação.

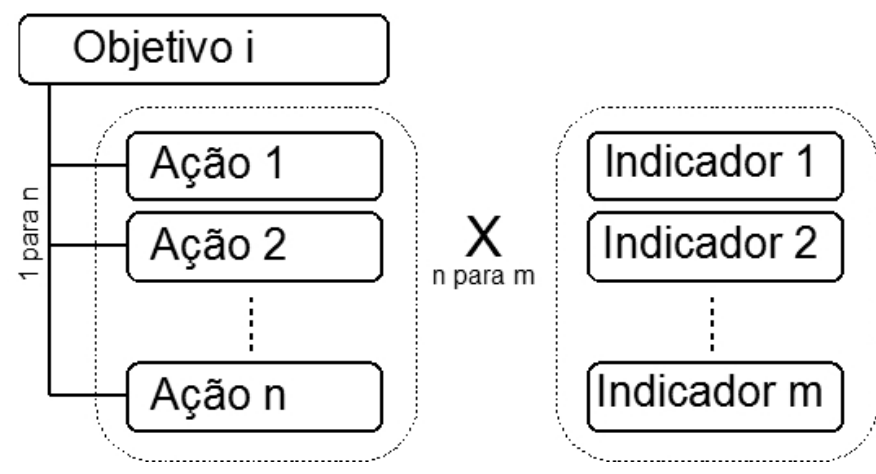

Figura 6: Relação entre os elementos das ações de desempenho

Cada uma destas ações possui um usuário responsável por ela. Esta pessoa pode criar sub-tarefas para sua ação de melhoria e delegá-las a diferentes usuários, o que favorece a colaboração na busca pela melhoria contínua.

\subsection{Implementação do software}

Um software foi implementado para atender os requisitos anteriormente apontados. Por isso, aqui são apresentadas suas principais funcionalidades por meio de figuras que simulam o software em funcionamento. Uma de suas principais funções é prover acesso rápido ao desempenho geral da organização. Para tal fim foi projeada uma tela inicial composta por gauges que mostram os principais indicadores de desempenho escolhidos pelo usuário. Cada usuário pode configurar o software para apresentar o conjunto de indicadores que mais interessa a ele. Para cada indicador há um gráfico que mostra o limite inferior e superior da meta junto com a evolução dos valores ao longo de um ano. Um exemplo disso pode ser visto na Figura 7. 


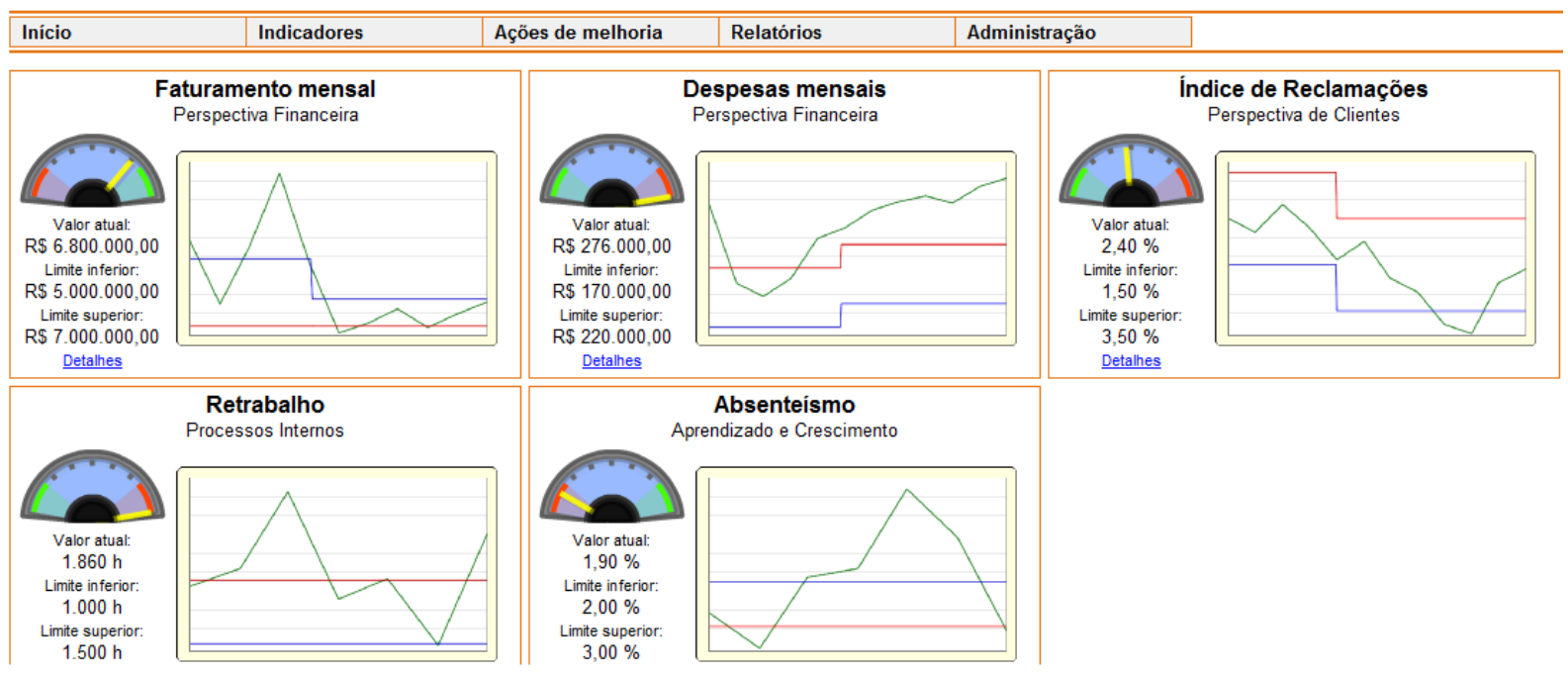

Figura 7: Tela inicial com os valores atuais de diversos indicadores de desempenho

Conforme o método apresentado para a construção do SMD, os indicadores devem ser organizados segundo a estrutura da Figura 5. Por isso, foi criada uma função para que o usuário possa navegar nas perspectivas e objetivos estratégicos e visualizar os indicadores de desempenho a eles associados. Esta funcionalidade, chamada de Árvore de indicadores, pode ser vista na Figura 8. Nessa tela, o usuário pode selecionar qualquer um dos indicadores da árvore e consultar informações relevantes a ele no lado direito da tela.
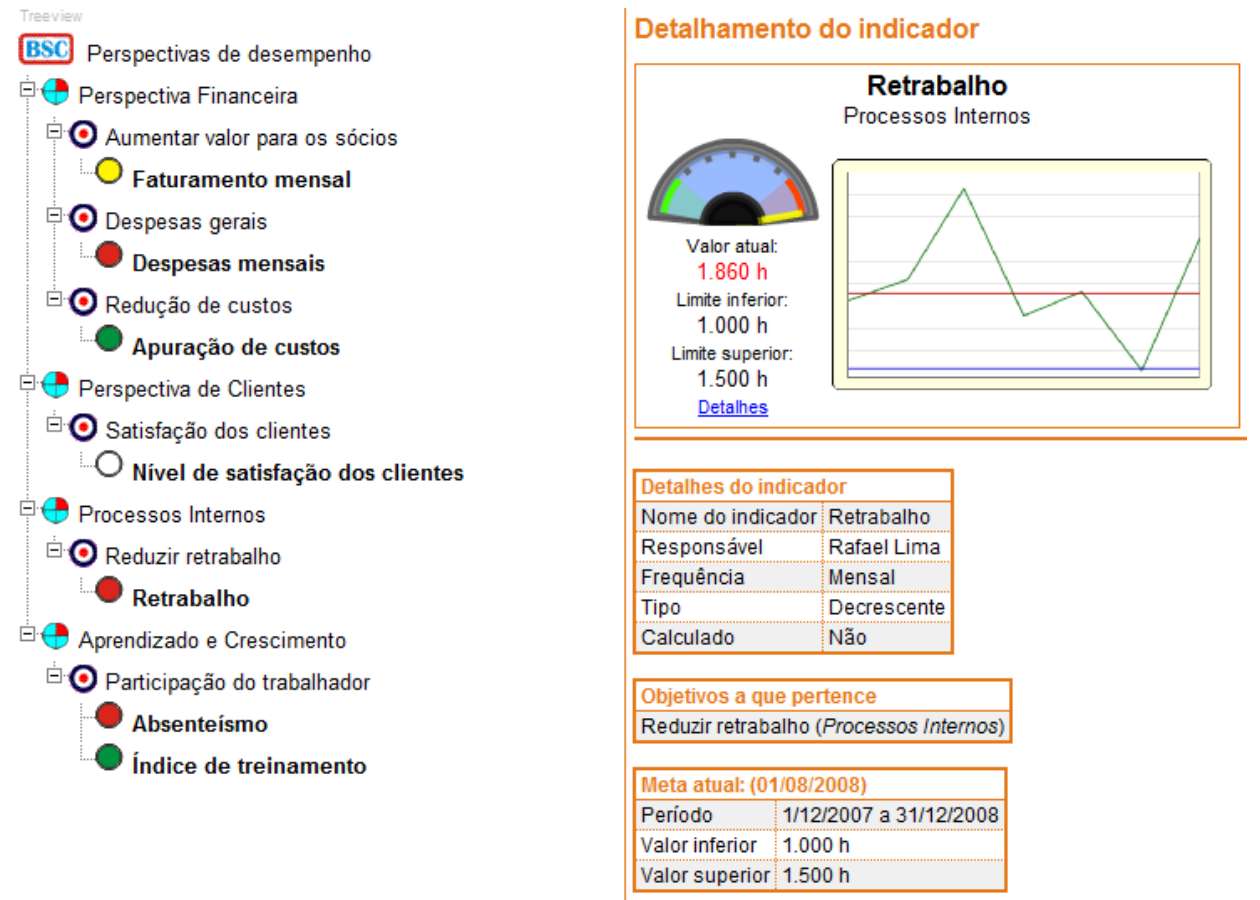

Figura 8: Árvore para navegação pelos indicadores de desempenho

Outro requisito do software é o gerencimento das ações de melhoria. De acordo com a Figura 6, a cada objetivo estratégico pode-se associar diversas ações de melhoria que visam aprimorar os resultados dos indicadores de desempenho. A criação de uma ação é vista como um projeto que deve ser elaborado segundo o 
método $5 \mathrm{~W} 1 \mathrm{H}$, no qual as sub-tarefas podem ser atribuídas a outros usuários. Um exemplo disso é mostrado na Figura 9.

Detalhamento da ação de melhoria

\begin{tabular}{|l|l|}
\hline Dados da ação de melhoria \\
\hline Nome & Melhoria nas embalagens protetoras \\
\hline Data de início & $01 / 10 / 2007$ \\
\hline $\begin{array}{l}\text { Data de término } \\
\text { (prevista) }\end{array}$ & $30 / 05 / 2008$ \\
\hline O que? & Uso de um novo tipo de embalagens protetoras para o envio dos produtos aos clientes. \\
\hline Por que? & Acredita-se que grande parte do retorno de produtos é devido à danos causados durante o transporte. \\
\hline Quem? & Rafael Lima \\
\hline $\begin{array}{l}\text { Como? } \\
\text { Indicadores } \\
\text { relacionados }\end{array}$ & definitiva. \\
\hline
\end{tabular}

Sub-itens da ação de melhoria (3 registro(s))

\begin{tabular}{|l|c|l|}
\hline \multicolumn{1}{|c|}{ O que?/Como? } & Quem? & Data limite \\
\hline Busca por novas opções de embalagens & Rafael Lima & $1 / 111 / 2007$ \\
\hline Teste das novas embalagens encontradas & Rafael Lima & $30 / 111 / 2007$ \\
\hline Contratação de um fornecedor para as embalagens & Rafael Lima & $15 / 12 / 2007$ \\
\hline
\end{tabular}

Figura 9: Exemplo de ação de melhoria que pode ser elaborada no software

Por fim, o sotware permite ao usuário criar relatórios para analisar os efeitos de uma ação de melhoria sobre os resultados dos indicadores. A Figura 10 mostra um exemplo de tal relatório, no qual se pode perceber que a ação realizada pode ter causado uma redução no valor médio do indicador Índice de retorno.

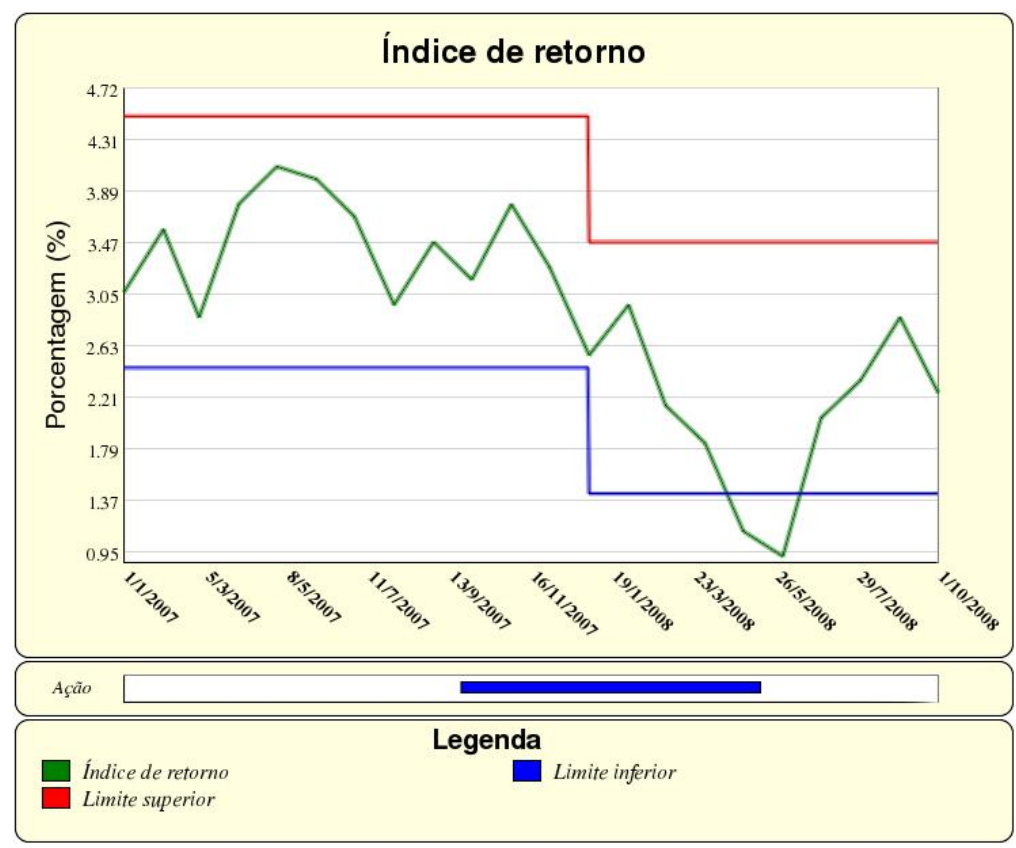

Figura 10: Relatório para analisar o efeito de uma ação de melhoria sobre o valor de um indicador

Além das funcionalidades aqui apresentadas, diversas outras foram implementadas para dar suporte ao sistema, tais como o cadastramento de 
usuários, permissões de acesso, inserção de coletas de indicadores, entre outras. No entanto, não é o objetivo deste artigo descrever a totalidade das funcionalidades implementadas, mas sim apresentar as mais importantes no contexto da gestão de desempenho.

\section{APLICAÇÃO PILOTO}

Conforme mencionado anteriormente, o método para construção de SMDs e o sistema informatizado de gestão de desempenho foram aplicados a uma empresa em caráter piloto. Logo, esta seção se dedica a reportar a aplicação, o que é feito por meio do relato de como os passos do método foram executados e como o software foi implantado.

\subsection{Aplicação do método para elaboração do SMD}

\section{Passo 1 - Compreensão do negócio da empresa}

A empresa que participou da aplicação piloto possui apenas dois diretores. Logo, foi preciso incluir neste passo entrevistas com os diretores e com outras pessoas-chave, sendo elas o gerente de marketing e o gerente de sistemas. Elas foram escolhidas por estarem na empresa há bastante tempo e por terem conhecimento de todos os processos organizacionais. Após as entrevistas, pôde-se definir o negócio principal da empresa, que é construir e comercializar caldeiras para usinas de cana-de-açúcar.

As entrevistas com os diretores visaram identificar os objetivos estratégicos da empresa referentes às quatro perspectivas do BSC. Os demais participantes das entrevistas colaboraram com a complementação dos objetivos estratégicos e a definição de alguns indicadores para eles. A participação do gerente de marketing foi muito importante na definição de objetivos relativos ao mercado, uma vez que ele já havia desenvolvido várias pesquisas sobre o mercado consumidor de caldeiras. $\mathrm{O}$ gerente de sistemas colaborou com informações sobre os processos internos e fontes de dados para os indicadores de desempenho.

\section{Passo 2 - Levantamento de indicadores atualmente em uso}

Os responsáveis por todas as áreas da empresa foram entrevistados para identificar os indicadores de desempenho em uso. A maioria desses indicadores foi criada pelos próprios responsáveis pelos departamentos e não foram integrados ao sistema de informação da empresa. Muitos deles são específicos e pontuais, não sendo interessantes para o acompanhamento de objetivos estratégicos. Por isso, apenas alguns deles foram selecionados para fazer parte do SMD, enquanto outros tiveram que ser criados ou ajustados. 


\section{Passo 3 - Compilação das entrevistas}

Primeiramente foram identificados os objetivos estratégicos com base nas entrevistas. Como esta foi a primeira vez que a empresa adotou um SMD formal, poucos objetivos estratégicos foram escolhidos para cada perspectiva. São eles:

- Perspectiva financeira:

1. Aumento do retorno sobre o capital investido;

2. Redução de custos;

- Perspectiva dos clientes:

3. Reconhecimento da marca da empresa;

- Processos internos:

4. $\quad$ Redução dos desperdícios;

- $\quad$ Aprendizado e crescimento:

5. Aumento da assiduidade dos funcionários.

Os indicadores de desempenho foram filtrados, dando-se preferência àqueles que tinham relação com os objetivos estratégicos. Outro critério usado para a seleção dos indicadores foi a existência de dados históricos e sua integração com os sistemas de informação. Após a filtragem, uma lista com os indicadores que atendiam a estes critérios foi feita. A lista foi cruzada com os objetivos estratégicos para identificar quais seriam úteis para o SMD. Após este cruzamento, os indicadores da Tabela 1 foram escolhidos para fazer parte da primeira versão do SMD. A frequência de coleta de todos estes indicadores é mensal.

\begin{tabular}{lll}
\hline Indicador & Descrição & Área \\
\hline Faturamento mensal & $\begin{array}{l}\text { Acompanha mensalmente o faturamento da } \\
\text { empresa }\end{array}$ & Contabilidade \\
Lucratividade & $\begin{array}{l}\text { Indicador baseado no DRE (Demonstração } \\
\text { do Resultado do Exercício), obtido pela } \\
\text { divisão do resultado líquido pelo total de } \\
\text { vendas. }\end{array}$ & Contabilidade \\
Número de propostas & $\begin{array}{l}\text { Acompanha a solicitação de propostas por } \\
\text { parte dos clientes. }\end{array}$ & Vendas \\
solicitadas & $\begin{array}{l}\text { Acompanha o total de custos por projeto, } \\
\text { comparando esse total com o valor orçado }\end{array}$ & \\
Resultado dos projetos & pela área comercial. \\
Calcula a porcentagem de horas gastas & Qualidade \\
Retrabalho & $\begin{array}{l}\text { com retrabalho em relação ao total de horas } \\
\text { trabalhadas. } \\
\text { Mede a porcentagem de horas de faltas em Recursos humanos } \\
\text { Absenteísmo }\end{array}$ & $\begin{array}{l}\text { relação ao total de horas que deveriam ter } \\
\text { sido cumpridas. }\end{array}$ \\
\hline
\end{tabular}

Tabela 1: Indicadores selecionados para o SMD

Os dois primeiros indicadores são ligados à perspectiva financeira e têm como objetivo medir os resultados financeiros. Esses indicadores são obtidos por meio do balanço contábil, que atualmente está informatizado e tem um grande histórico de dados. O acompanhamento desses indicadores é muito importante, pois, segundo os diretores, existe uma grande sazonalidade no faturamento. Por se tratar de um produto cujo valor unitário é muito alto, no mês em que uma caldeira é comercializada o faturamento aumenta muito em relação aos meses nos quais nenhuma nova caldeira foi faturada. 
A empresa não possui um número muito alto de clientes, pois as caldeiras são produtos muito grandes e complexos e levam muito tempo para serem finalizados. Portanto, a empresa não considera necessário um sistema informatizado para controle de clientes. O relacionamento com os clientes é feito pessoalmente, ou por meio de correspondências ou emails, sem nenhum controle formal. Um indicador identificado pela área de marketing é o controle de propostas solicitadas para a área de vendas. A empresa não possui vendedores e as propostas chegam por email para esta área, que calcula o orçamento e o envia de volta para o cliente. Esse indicador, que contabiliza o número e o valor dos orçamentos, foi considerado importante por mostrar como a empresa está conhecida no mercado e também serve para prospectar novos clientes. Outra utilidade desse controle é a possibilidade de comparar o valor total orçado com o valor dos negócios realmente fechados.

O resultado dos projetos é um fator crítico dentro da empresa, uma vez que é muito difícil prever o custo de um produto grande e complexo como uma caldeira. $A$ empresa possui uma tabela de custos para que a área de vendas possa elaborar orçamentos mais precisos. No entanto, o acompanhamento dos custos de um projeto é essencial para que a empresa saiba se está tendo lucro. O objetivo deste indicador é melhorar a capacidade de prever o valor de um produto e buscar possibilidades para reduzir os custos dos projetos.

O indicador de retrabalho está em implantação dentro da empresa e visa apontar a quantidade de horas gastas com reprocessamento ou correção de defeitos em cada projeto. A grande dificuldade está no apontamento correto das horas, o que deve ser feito por meio eletrônico pelos funcionários. No entanto, ainda há certa resistência por parte dos funcionários em apontar as horas de retrabalho, o que torna os valores imprecisos. A empresa atualmente está realizando trabalhos de conscientização dos funcionários para melhorar este quadro.

Por fim, o absenteísmo mede a porcentagem de horas de faltas dos funcionários. Esse fator é crítico, pois a empresa calcula seu trabalho semanal com base nas horas de trabalho disponíveis. Quanto mais horas a empresa perder com faltas, acidentes e afastamentos, maiores serão as chances de atrasos nos projetos.

\section{Passo 4 - Refinamento do SMD}

A apresentação dos objetivos estratégicos e indicadores de desempenho foi feita durante o treinamento dos usuários do software de gestão de desempenho. Com isso, os usuários puderam ter uma visão geral do software e do SMD e saber qual seria sua abrangência dentro da empresa. Nenhuma sugestão foi feita para modificação de objetivos e indicadores, uma vez que esta versão do SMD ainda é reduzida. Após a aprovação desta primeira versão, ela foi configurada no sistema e pôde ser dado o início ao seu uso.

\section{Passo 5 - Plano de implantação}

Um cronograma para implantação do SMD foi elaborado. Este cronograma incluiu prazos para a integração dos sistemas, importação de dados anteriores e treinamento do pessoal. Também foi definido que a manutenção do sistema deveria ser anual. Com isso, após um ano de uso desta versão inicial, uma nova versão do SMD deverá ser elaborada de forma mais completa. 
A implantação do software para gestão de desempenho ocorreu paralelamente à modelagem do SMD. As atividades realizadas para concluir a implantação foram as seguintes:

1. Instalação do software: o software foi instalado no servidor da empresa de forma que todos os usuários pudessem usar o sistema por meio de um navegador web. Isso tornou a tarefa de implantação simplificada, pois a centralização da base de dados e da aplicação no servidor economizou o tempo que seria gasto caso a instalação tivesse que ser feita em cada terminal de usuário;

2. Parametrização do software: os objetivos estratégicos, indicadores de desempenho e as metas para o ano foram configurados no software. Além disso, esta tarefa incluiu o cadastramento dos usuários e a atribuição de responsabilidades pelos indicadores;

3. Importação dos dados: os usuários responsáveis por cada indicador de desempenho reuniram os dados das coletas existentes anteriormente e as cadastraram no software;

4. Treinamento: o treinamento dos usuários finais foi feito focando as funcionalidades cotidianas do sistema, que são o acompanhamento e alimentação de indicadores. Participaram deste treinamento os responsáveis pelas áreas que possuíam indicadores, conforme mostrado na Tabela 1 . Um treinamento para configuração e manutenção do sistema foi feito separadamente com os funcionários responsáveis pela área de sistemas de informação;

5. Acompanhamento: durante os três primeiros meses após o término da instalação e treinamento, um acompanhamento foi feito para auxiliar na coleta e registro dos dados dos indicadores. Relatórios de desempenho mensal foram gerados para verificar o desempenho da empresa quanto aos seus objetivos.

\section{CONCLUSÕES}

Este artigo apresentou um método para elaboração de SMDs compostos por perspectivas de desempenho, objetivos estratégicos e indicadores. Também foi apresentado um software para a gestão do desempenho organizacional, pelo qual os indicadores podem ser monitorados e ações de melhoria podem ser criadas e geridas. O método foi testado em uma empresa, dando origem a um sistema de indicadores de desempenho formalizado. O software foi então aplicado de acordo com o SMD obtido pelo método.

Quanto ao SMD construído, pode-se dizer que ele ainda é uma versão preliminar e precisa ser melhorado ao longo das revisões anuais. Isto se deve ao fato de o número de indicadores e objetivos estratégicos ainda ser muito pequeno para a gestão apropriada do desempenho organizacional. A opção por uma aplicação reduzida foi feita para se testar tanto o método quanto o software em 
meios menos complexos. Assim, a empresa poderia aprender mais sobre as potencialidades do software e aumentar gradativamente seu número de indicadores e objetivos.

Algumas dificuldades tiveram que ser superadas durante o desenvolvimento deste projeto. A principal delas foi o comprometimento da empresa com a medição de desempenho. Como ela não havia desenvolvido até então trabalhos neste sentido e o número de funcionários disponíveis para o projeto era reduzido, muitos atrasos ocorreram. Outra dificuldade encontrada foi a falta de precisão de alguns dos dados dos indicadores. Em muitos casos, os dados de indicadores como horas de retrabalho ou custos de projetos eram imprecisos. Isso se devia tanto à coleta manual de dados quanto à inexistência desses dados nos sistemas corporativos, 0 que poderia diminuir a precisão do SMD como um todo.

Uma das características essenciais do software aqui apresentado é seu apelo gerencial. Seu foco está na organização de indicadores quanto à estratégia organizacional. Por isso, seus usuários devem ser pessoas ligadas à gerência ou à direção da empresa, pois por meio deste software elas podem ter uma visão do desempenho de uma forma generalizada. Este fato transforma o software em uma ferramenta inapropriada para medição de desempenho de temas específicos, como, por exemplo, o tempo de processamento de uma determinada máquina no chão-defábrica. Este tipo de informação, que não é importante no nível gerencial, deve ser evitado no software aqui desenvolvido.

Um ponto positivo da aplicação do método foi a organização dos indicadores de forma mais concisa. A empresa já possuía indicadores de desempenho, mas nunca havia desenvolvido um SMD formalizado. Os indicadores eram usados apenas para problemas pontuais e não havia um alinhamento dos indicadores à estratégia organizacional. A criação de novos indicadores se dava devido à necessidade e os dados coletados não eram divulgados de maneira apropriada na organização. Em muitos casos, os indicadores ficavam limitados apenas aos próprios setores que os desenvolviam.

Uma das vantagens do uso software é a comunicação do desempenho. Como todos os dados dos indicadores estão nele armazenados, todos os usuários que têm acesso ao software podem gerar relatórios sobre os indicadores e ações de melhoria à eles relacionadas. Como os relatórios seguem um formato padrão, o entendimento de seu conteúdo se torna mais fácil e eles podem ser usados em reuniões para discussão e tomada de decisões.

De modo geral, tanto a aplicação do método quando do software foram bem sucedidas. Contudo, aplicações em outras empresas devem ser feitas para buscar limitações e oportunidades de melhoria. Algumas questões ficam ainda em aberto, tais como a constatação na prática dos efeitos das ações de melhoria sobre o desempenho dos indicadores e a forma como o SMD deve ser avaliado e atualizado.

\section{ABSTRACT}

The appropriate management of performance measures and strategic objectives may become a success factor for businesses and allow them to achieve similar or even better performance results against their competitors, which is vital for companies to thrive in today's competitive marketplace. Thus, new tools and methods for performance measurement system (PMS) design must be developed in order to 
contribute to this research field. Moreover, these tools and methods need to be assessed through empirical applications to prove their efficiency and effectiveness. The objective of this article is thus to propose a method for PMS design and an information system (IS) to keep track of the performance measures that resulted from this method. The IS also assists companies in managing improvement initiatives and associate them with performance measures. Both the method and software were tested through action research in a real case. After the field research, the method was found to be efficient for performance measures selection. The software, on its turn, can be viewed as a good means of communicating performance and fostering continuous improvement.

Keywords: Performance management, Balanced scorecard, Decision support systems.

\section{REFERÊNCIAS}

ADAMS, C.; NEELY, A. The performance prism to boost M\&A success. Measuring business excellence, v. 4, n. 3, p. 19-23, 2000.

AMARATUNGA, D.; BALDRY, D. Moving from performance measurement to performance management. Facilities, v. 20, n. 5, p. 217-223, 2002.

ATKINSON, H. Strategy implementation: a role for the balanced scorecard? Management Decision, v. 44, n. 10, p. 1441-1460, 2006.

BASU, C. et al. Difusion of executive information systems in organizations and the shift to web technologies. Industrial management \& data systems, v. 100, n. 6, p. 271-276, 2000.

BOURNE, M.; KENNERLEY, M.; FRANCO-SANTOS, M. Managing through measures: a study of impact on performance. International Journal of Operations \& Production Management, v. 16, n. 4, p. 373-395, 2005.

BOURNE, M. et al. Designing, implementing and updating performance measurement systems. International Journal of Operations \& Production Management, v. 20, n. 7, p. 754-771, 2000.

BRIGNALL, T. J. The unbalanced scorecard: a social and environmental critique. In: NEELY, A., WALTERS, A., AUSTIN, R. Performance Measurement and Management: Research and Action, Performance Measurement Association. Boston, 2002.

CAMPOS, V. F. Gerenciamento pelas diretrizes: o que todo membro da alta administraçãoprecisa saber para entrar no terceiro milênio. Belo Horizonte: UFMG, 1996. 
CHAVAN, M. The balanced scorecard: a new challenge. Journal of management development, v. 28, n. 5, p. 393-406, 2009.

COLLINS, B.; HUGE, E. Management by policy: how companies focus their total quality efforts to achieve competitive advantage. Milwaukee: ASQC Quality Press, 1993.

FOLAN, P.; BROWNE, J. A review of performance measurement: towards performance management. Computers in industry, v. 56, n. 7, p. 663-680, 2005.

GOMES, C. F.; YASIN, M. M.; LISBOA, J. V. A literature review of manufacturing performance measures and measurement in an organizational context: a framework and direction for future research. Journal of Manufacturing Technology Management, v. 15, n. 6, p. 511-530, 2004.

HIKAGE, O.; SPINOLA, M.; LAURINDO, F. Software de balanced scorecard: proposta de um roteiro de implantação. Produção, v. 16, n. 1, p. 140-160, 2006.

HUDSON, M.; SMART, A.; BOURNE, M. Theory and practice in sme performance measurement system. International Journal of Operations \& Production Management, v. 26, n. 8, p. 1096-1115, 2001.

KAPLAN, R.; NORTON, D. The balanced scorecard: measures that drive performance. Harvard Business Review, January-February, p. 71-79, 1992.

KAPLAN, R.; NORTON, D. A Estratégia em Ação: Balanced Scorecard. Rio de Janeiro: Campus, 1997.

KAPLAN, R; NORTON, D. Transforming the balanced scorecard from performance measurement to strategic management: part I. Accounting Horizons, v. 15, n. 1, p. 87-107, 2001

KAPLAN, R.; NORTON, D. Mapas estratégicos: convertendo ativos intangíveis em resultados tangíveis. Rio de Janeiro: Campus, 2004.

KEEGAN, D. P.; EILER, R. G.; JONES, C. R. Are your performance measures obsolete? Management Accounting, June, p. 45-50, 1989.

LYNCH, R. L.; CROSS, K. F. Measure Up - the Essential Guide to Measuring Business Performance. London: Mandarian, 1991.

NEELY, A. The performance measurement revolution: why now and what next? International Journal of Operations and Production Management, v. 19, n. 2, p. 205228, 1999.

NEELY, A. The evolution of performance measurement research - developments in the last decade and a research agenda for the next. International Journal of Operations \& Production Management, v. 25, n. 12, p. 1264-1277, 2005. 
NEELY, A.; ADAMS, C.; CROWE, P. The performance prism in practice. Measuring business excellence, v. 5, n. 2, p. 6-12, 2001.

NEELY, A.; BOURNE, M.; KENNERLEY, M. Performance measurement system design: developing and testing a process-based approach. International Journal of Operations \& Production Management, v. 20, n. 10, p. 1119-1145, 2000.

NEELY, A.; GREGORY, M.; PLATTS, K. Performance measurement system design. a literature review and research agenda. International Journal of Operations and Production Management, v. 15, n. 4, p. 80-116, 1995.

NORREKLIT, $\mathrm{H}$. The balanced on the balanced scorecard - a critical analysis of some of its assumptions. Management Accounting Review, n. 11, p. 65-88, 2000.

NUDURUPATI, S.; BITITCI, U. Implementation and impact of IT-supported performance measurement systems. Production Planning \& Control, v.16, n.2, p.152-162, 2005.

O‘BRIEN, J. Sistemas de Informação e as decisões na era da internet. São Paulo: Editora Saraiva, 2004.

OLSEN, E. O. et al. Performance measurement system and relationships with performance results: A case analysis of a continuous improvement approach to PMS design. International Journal of Productivity and Performance Management, v. 56, n. 7, p. 559-582, 2007.

OLVE, N. G.; ROY, J.; WETTER, M. Condutores da Performance. Rio de Janeiro:: Qualitymark, 2001.

POE, V.; KLAUER, P.; BROBST, S. Building a data warehouse for decision support. Upper Saddle River: PTR, 1997.

RENTES, A.; CARPINETTI, L.; AKEN, V. Measurement system development process: a pilot application and recommendations. In: Anais do PMA Conference. Boston, 2002.

SOUSA, S.; ASPINWALL, E.; RODRIGUES, A. Performance measurement in English small and medium enterprises: survey results. Benchmarking: An International Journal, 2006.

TURBAN, E.; RONSON, J. Decision Support Systems and Intelligent Systems. Upper Saddle River: Prentice Hall, 2001.

VOELPEL, S.C.; LEIBOLD, M.; ECKHOFF, R.A. The tyranny of the balanced scorecard in the innovation economy. Journal of Intellectual Capital, v. 7, n. 1, p. 43$60,2006$.

WISNER, J.; FAWCETT, S. Link firm strategy to operating decisions through performance measurement. Production and Inventory Management Journal, p. 5-11, Third Quarter, 1991. 